\title{
Malmkjær, K., Şerban, A., \& Louwagie, F. (Eds.). (2018). Key cultural texts in translation. John Benjamins. 320 pp.
}

Key Cultural Texts in Translation is a book that yields its riches on second sight. In the prepandemic days, when we still wandered into each other's offices in analogue fashion, colleagues spotting the volume on my desk curiously yet invariably misread its title as 'key texts in cultural translation'. This, however, is not a greatest hits-type collection of seminal papers on cultural translation (whatever we may mean by that increasingly contentious phrase). Rather, the texts under scrutiny in this volume are source and target texts from a variety of types, genres and forms. Their status as 'Key Cultural Texts' derives from the pivotal function they are said to perform in their source domains, where, as the editors explain in their short introduction, they "play central roles in presenting and representing the culture to itself and in defining its cultural others" (p. 1). What happens to such Key Cultural Texts when they are translated is the central and unifying focus of the contributions gathered in this volume, which partly stem from work done under an AHRC networking grant on "Key Cultural Texts in Translation" and partly from an EST 2013 panel on the same theme. Key cultural texts in translation, then, are texts that are "considered important in [their] source culture and ha[ve] contributed to the shaping of that culture. In translation, [they] would have had influence on the target culture and changed that culture in some way" (p. 2).

Cultures, in this volume, are more often than not taken to be national cultures, and the temptation to present source cultures in particular as relatively monolithic entities, without detailed analysis of, or reflection on, their own constructedness, is one that not all contributions manage to eschew. In the preface, the editors briefly highlight this aspect of constructedness in relation to the "key concepts" that the Key Cultural Texts considered in this volume "embody" and "help to define" (p. 1). Quoting Chomsky $(1979$, p.38) on the "limits of possible thought" that such concepts can impose, and Gallie (1956, p. 193) on the importance of recognising any "given concept as essentially contested" gestures in the right direction here. However, these twin insights could, and should, have also been extended to the concept of culture itself - and, for that matter, to the concept of translation. This would have served as a useful steppingstone for a fuller and conceptually richer exposition of the Key Cultural Texts in Translation project's tenets and parameters of discussion than the four and a half introductory pages offered by the editors provide. As it stands, the task of destabilising "key concepts" and "highlight[ing] the essentially contested nature of certain concepts across cultures" (p. 1) is squarely assigned to translation, which, as the editors note, "can disturb" Chomsky's "limits of possible thought" (p. 1) and "enabl[e] disturbances of perceived relations of periphery versus centrality among cultural groups and the concepts that are embodied in the texts that they consider central to their cultures" (p. 2). The stance adopted by the editors here rightly casts scholarly engagement with translation(s) of Key Cultural Text as an endeavour "from which significant learning can be derived" (p. 1). However, I was left wondering whether more than "reasons for re-translation, revealing perceived miscommunications or felt need to greater precision", "perceived translation difficulties and the reasons for them", "the solutions adopted, and the reasons for those" ( $p$. 1 ), and "patterns of similarities and difference in the treatment in translations of key cultural 
concepts" (p. 2) could have been uncovered with a more nuanced and conceptually more dynamic framework of enquiry.

The volume is organised into six sections, each comprising two to four individual contributions grouped under a given theme. To discuss and do justice to each of the seventeen contributions is beyond the scope of this review, so I will highlight one or two papers per section that, to me, stood out for one reason or another.

In Part I: Gender and Identity comprises Stella Sandford on "Genos, sex, gender and genre" and Ourania Tisakalou's article on "Dancing through the waves of feminism: Martha Graham and Marie Choinard as intersemiotic translators". The focus here will be on Sandford's fascinating exploration of the English translation of Classical Greek genos as "sex" in Book V of Plato's Republic. This translation decision, Sandford contends, is a strategically domesticating move on the part of a succession of English translators of the Republic that superimposes the "modern natural-biological concept of sex", in the sense of sex difference based on the assumption that "there simply is sex duality (the exclusive division between male and female) and that [this] duality is naturally determined" (p. 11), onto an ancient text that, in fact, does not share these "modern presumptions about sex" (p. 12) and whose language does not even have a "distinct word for sex" (p. 16). The result, according to Sandford, is not only a questionable ex post facto legitimatisation (and de-historicisation) of the "key, modern, identify defining concept" of sex as a "basal explanans" of difference ( $p$. 20), but also an obscurance of the Republic's "philosophical intelligibility" (p. 18) that precludes alternative and more historically informed readings. Such alternative readings, which Sandford demonstrates as perfectly possible in her analysis of pertinent passages from Book V, centre on the "commutability of womanishness and manliness" (p. 19) in Socratic thought. They also allow her to show that the modern concept of sex, in spite of its claims to universality and thus unchallengeability, "is in fact contestable, and that analysis of translations reveals both its assumptions in the translating culture and textual reasons to dispute its alleged transhistorical significance" (p. 21). In an illuminating coda, Sandford extends this argument to a brief exploration of the changing fates of the English terms 'gender' in contemporary French discourse, highlighting the deeply political motivations for and against, on the one hand, non-translation that marks 'gender' "as belonging to an American culture, or a culture of Americanisation, against which many wished to reassert l'exception française" (p. 22), and, on the other, the conscious use of genre as a vernacular translation of 'gender' as both a conscious "political choice" and a rejection of "linguistic nationalism" (p. 23). Taken together, Sandford's critical reading of the Republic and her deliberations on Anglophone gender theory in France convincingly "demonstrate how translation and its analysis may become both the mode of expression of assumptions about sex and gender, and simultaneously the site of contestation of these assumptions" (p. 10).

Part II: Texts and Politics opens with Helen Rawling's “Bartolomé de Las Casas' Breve Relación de la Destrucción de Las Indias (Brief Account of the Destruction of the Indies) (1542) in translation: The politics of linguistic and cultural appropriation", an account of the appropriation, through translation, of a text originally intended to expose conquistador atrocities in the New World into a propaganda weapon instrumental in building the Spanish Black Legend narrative. This is followed by Karen Wilson-de Roze's deliberations on the question "Have English translations of Wagner's Ring of the Nibelung, an icon on German culture, been affected by the changing relationship between Germany and Britain in the 
twentieth century?". I will here focus on the third paper in this section, Marta Crickmar's "Communicating change: Two contemporary Polish novels in translation into English". The two contemporary Polish novels in question are Dorota Masłowska's Wojna polsko-rusak pod flagq baiło-czerwonq (translated by Benjamin Paloff as Snow White and Russian Red (US) and White and Red (UK)) and Michał Witkowski's Lubiewo (translated by William Martin as Lovetown). Both are characterised by their sub-cultural setting - the world of disaffected skinheads in Masłowska's novel and that of an assortment of ageing gay characters in Witkowski's. Crickmar contends that both are "key cultural texts, as each is an important voice in the discussion on contemporary Poland's struggle with its identity" (p. 80), and both were "marketed in the English-speaking world as showing valuable insights into the new postcommunist Polish reality" (p. 83). To what extent they fulfil the second part of the Key Cultural Texts definition offered in the volume's preface, namely that they "would have had influence on the target culture and changed that culture in some way", is a question Crickmar explores in relation to losses and gains, and within a polysystems-inspired framework. Charting networks of signification that rely heavily on historical, socio-cultural, sociolinguistic and intertextual specificities in both novels, Crickmar's emphasis is on the difficulties these pose to translators, both at a textual level and in terms of "Polish literature in English translation [...] still [being] a peripheral or, at best, a semi-peripheral system" (p. 82). Somewhat unsurprisingly, the losses chalked up far outweigh the gains within this scheme of enquiry as the networks of signification under scrutiny here "consist of culture-specific items for which there are no straightforward equivalents" (p. 85). To compound matters, they are inevitably subject to domesticating strategies that reflect their transposition from Polish periphery to Anglophone centre. This leads Crickmar to conclude that 'these works' status as key cultural texts has not (and could not have) been transferred" (p. 90). This is, to some extent, obvious enough. Crickmar, however, also closes on a more hopeful note that would have borne fuller exploration in the context of this volume: "Frank Kermode said canonical texts must be granted the 'blessing of change'. I would say, the status of key cultural texts must be granted the same privilege in translation' (p. 91). Quite.

Part III: Texts and Places groups together Jurgita Vaičenoniè's corpus-based analysis of "Lithuanian literature in English: Two English translations of Romualdas Granauska's short story 'The bread eaters' (1975)"; Myrte Wouterse and Samantha Genegel's "Woest of the Wild: Translating Yorkshire culture in Emily Brontë's Wuthering Heights", where the emphasis is on translating, or attempting to translate, "topology and dialect as representations of cultural identity" (p. 115); and Anna Ponomareva's "Polish Dance in Eugene Onegin: What can be found in translation", where the translation of culture-specific concepts and terms once again forms the focus of attention. Ponomareva's interest, however, lies precisely not in the relative untranslatability of such culturally specific elements, but rather in textual strategies that enable their retention in translation, and thus their introduction to target audiences across time. Citing Venuti as an explicit influence, she describes her focus as aiming "to move from studying accuracy or equivalence between source and target text to discussions what one's translation brings to its target audiences" (p. 132). The substantive overview of English translations of Eugene Onegin, ranging from Spalding's 1881 translation through to Hoyt's and Mitchell's, both dating from 2008, is not only of interest to historians of translation, but also makes the case that there is "added value" (p. 134) in both individual and cumulative translations that "complement, not supplement the original" (p. 136) - and indeed each other. Ponomareva's subsequent exploration of a variety of paratextual materials adds 
concrete depth to this discussion and prepares the ground for her - regrettably brief comparative analysis of five English renderings of selected dance passages from Eugene Onegin as instructive instances of "the peculiarities of semantics and syntax through which Russian culture comes to its English-speaking audiences" (p. 145). From these, Ponomareva concludes that the translatability of culture-bound symbolic structures succeeds to the precise extent to which "translators are free from the constraints of a search for equivalence" (p. 147). While this is an undoubtedly refreshing (though not earth-shatteringly new) insight, this paper, like others in this volume, would have been enriched further by a more dynamic, less monolithic, conception of the source culture in particular.

Part IV: Occident and Orient, framed somewhat stereotypically by the editors as "set[ting] the two 'worlds' in mutual relief through the study of texts and their translations" (p. 4), comprises four papers: Kelly Kar Yue Chan's "The cultural transformation of classical Chinese poetry in translation into English", another exploration of "the level of untranslatability embedded in cultural elements" (p. 171); Hanting Pan's CDA-informed and corpus-based investigation of "The immigration of key cultural icons: A case study of church name translation in Macao"; Jinsil Choi's "Reproduction and reception of the concepts of Confucianism, Buddhism and polygamy: Kuunmong in translation", which focuses on the target-context sensibilities shaping (to put it mildly) two English translations of the classic Korean novel Kuunmong; and Wenjie Li's "The image of H. C. Andersen's tales in China (19091925): A case study of a set of Key Cultural Texts in translation", which I am going to focus on here. Li charts the role that Chinese translations of Andersen's tales played in the period leading up to and including the May Fourth Movement, particularly in forging alternative conceptions of childhood and thus participating in a wider intellectual enterprise of translating "foreign", and specifically Western, "literatures [...] as prescriptions for curing China's social problems" (p. 156). The paper is rich in detail on the key players involved in the translation and popularisation of Andersen in China, as well as on the media, stylistic programme, and wider intellectual context in which their translation activities were situated. The fact that "none of the people involved in the introduction and translation of Andersen's tales during this period could read Danish", as a result of which "their interpretations and translations had to take a detour via mediating translations in other, major languages" ( $p$. 161) - namely English - is given due prominence in the discussion. The same holds true for Li's forensic tracing of both the (often multiple) English translations that served as sources for the Chinese texts, and the English-language Andersen criticism that further shaped the translators' readings of his tales. $L i$ is thus able to conclude her paper with a section aptly titled 'The translated image of $\mathrm{H}$. C. Andersen', where indirectness becomes a positive organising principle not only of "the image(s) transferred by, or forged in or through translational activities like text-selection, translating, introduction, interpretation, reception, etc." (p. 164), but also of the role translations play "in defining and re-defining [...] cultural concepts" (p. 169) in the target culture.

Part V: Translating Philosophy opens with David Charlston's excellent paper on "Hegel's Phenomenology: A comparative analysis of translatorial hexis", which addresses how translators of philosophical texts "do and/or should [...] participate in the ideological debate surrounding the (key cultural) texts they translate" (p. 222). Charlston convincingly argues that translators of philosophy do not occupy neutral ground when it comes to the accumulation of economic, symbolic, and cultural capital, and exhorts us to "openly acknowledg[e] the fact that translators must necessarily participate critically in the 
communication and re-narration of their own understanding" (p. 222) of the text they are translating and offering in translation. Drawing on Bourdieu, he retraces such re-narrations, be they tacit or acknowledged, across a range of English translations of Hegel's Phenomenology of Mind (or Spirit, depending on the translation). Indeed, Charlston's illuminating comparative analysis of Baillie's first translation, published in 1910, and Pinkard's 2008 translation of Phenomenology centres on the consequential choice between 'mind' and 'spirit' for Geist, which, as Charlston shows, necessarily, and in each instance, renders the very act of translation one of "legislation, not merely mediation" (p. 225). Charlston's overarching framework of "translatorial hexis, which is intended to link the translator's subtle but inevitable re-structuring of Hegel's text, [...] with the structured, social micro-dynamics of the highly competitive academic sub-fields in which the translators worked" (p. 223) is well chosen to demonstrate how translators are indeed both "structured and structuring' agents" (p. 223), their choices "subtle [...] but not ethically neutral" (p. 231), and their translations actively involved in "re-shaping concepts" that centrally contribute "to their readers' conceptualisation of individual and cultural identities at the centres and also at the peripheries of world power" (p. 231).

Stefan Baumgarten's equally illuminating "Adorno refracted: German critical theory in the neoliberal world order" is the second of the two papers in the Translating philosophy section of Key Cultural Texts in Translation. Baumgarten examines Adorno in English "as refracted through a positivist order of discourse" (p. 235) and interrogates the "translational recontextualization" of "non-identity thinking" (ibid.), a key constitutive figure of thought (and style) in Adorno's work, into Anglophone philosophical discourse as a series of "forcible appropriations" (p. 241) that transform Adorno's "strictly non-identitarian ontology into an easily digestible market commodity" (p. 240). Baumgarten is, rightly, at pains to point out that his "observations should not be mistaken for a conservative critique that laments the misrepresentation of an 'original' author on teleological grounds" (p. 241). Rather, his critique is directed at "poorly self-reflexive English-language representations of German critical theory [that] tend to materialise as images without resemblance, as simulacra whose only trace of origin lies in reified cognition" (p. 250). Baumgarten does, however, also detect hopeful tendencies in more recent English translations of Adorno's work. Robert Hullot-Kentor's 1997 translation of Ästhetische Theorie and Dennis Redmond's 2005 translation of Minima Moralia in particular represent translational interventions that reject "enforced comprehensibility" (p. 240) and an identitarian mindset that "assumes an illusory resemblance to otherness that it can never achieve" (p. 250). Instead, they embrace Adorno's often aphoristic and concentric compositional principles to achieve a "terse and self-contained yet wholly interdependent and outreaching discourse" (p. 247) in English. It is on the basis of his meticulously detailed and well-argued comparative analysis of these translations and their predecessors that Baumgarten's fine piece ultimately stands as an effective call to address translation theory's continuing lack of a "convincing critical deconstruction of capitalist presuppositions" that could, and should, lift "the veil that consumer capitalism casts over normative translation behaviour and by extension over the constitutions of literatures in translation" (p. 250).

Part VI: Text Types brings together Muhammad J. H. Abdullatief on "Cultural satirical features in translation: The Pessoptimist as a case study", Jacobus A. Naude and Cynthia L. MillerNaude on "Alterity, orality and performance in Bible translation", and, as the opening paper of this section, Turo Rautaoja's contribution on "Constructions of a cultural narrative through translation: Texts on Sibelius and his works as Key Cultural Texts". Rautaoja offers a solid and 
insightful case study of the central role translations have so often played, and still play, in constructing narratives of national identity. His focus here is on the emergence and solidification, centrally and indeed exclusively enabled by translations of biographical and musicological texts from German, Swedish, and English into Finnish, of the figure of Sibelius "as the father of Finnish music and embodiment of Finnish nationhood and patriotism" ( $p$. 257). The eleven texts under scrutiny here span the period between 1916 and 1960, and it is the fact that they become Key Cultural Texts through translation that allows Rautaoja's contribution to add a particularly original dimension to the volume as a whole. The complex intertextual relationships that sustain these texts are one of several aspects that contribute, according to Rautaoja, to the remarkable longevity of the Sibelius myth they collectively erect. Through nuanced grouping and sustained analysis of these interwoven texts, Rautaoja is also able to show that their translations were, however, not simply appropriated "to develop and sustain the ideals that the nation perceived itself to possess", but also, if perhaps inadvertently, proved instrumental in "introduc[ing] new ideas that perhaps were still too controversial to be expressed unaided by the target culture" (p. 272). They thus stand as Key Cultural Texts that simultaneously reflect and refract Finnish nationalism in the twentieth century.

In many ways, Key Cultural Texts in Translation reads less like the concluding publication to a five-year project and more like a beginning - an invitation, that is, to explore and further probe the considerable variety of approaches to the "ways in which texts can express cultural identity and in which this expression of identity can be maintained and developed in translation" (p. 5). This is not necessarily a weakness. The range of critical outlooks and textual foci offered in this volume holds the potential for a rich variety of theoretical perspectives to be brought into productive play with one another. To this reader, such bringing-into-play remains, however, a still outstanding task - one that could, and should, lead to a necessarily open yet more explicitly articulated conceptual framework within which the role of translation in the formation and articulation of culture(s) can be discussed further. As it stands, Key Cultural Texts in Translation illustrates both the immense richness of responses its basic research question managed to elicit from scholars of a wide range of theoretical and disciplinary persuasions, and the elusiveness of some of the conceptual spirits it has cited.

\section{References}

Chomsky, N. (1979). Language and responsibility: Based on conversations with Mitsou Ronat. Pantheon.

Gallie, W. B. (1956). Essentially contested concepts. Proceedings of the Aristotelian Society, 56, 167198.

\section{Alexa Alfer}

University of Westminster

A.Alfer01 @westminster.ac.uk 